\title{
Productivity of crop rotation using fertilizers and herbicides in the Vologda Oblast
}

\author{
Olga Chukhina*, Nadezhda Tokareva, Anna Demidova, Tatyana Vasilieva, Elena Karbasnikova, and Natalya \\ Shchekutieva \\ Vologda State Dairy Farming Academy, 160555 Vologda, Russia
}

\begin{abstract}
The work shows that in the Vologda region on sod-podzolic medium loamy soil, the use of various doses of fertilizers significantly increased the productivity of rotation crops both with and without herbicides. Fertilizer doses calculated by the balance method for the planned yield using the balance coefficients of nutrient utilization from fertilizers and soil increased the removal of nitrogen, phosphorus, potassium, both by crops and weeds, compared to the control.
\end{abstract}

\section{Introduction}

A sufficient amount of heat and often an excess of precipitation (hydrothermal index greater than 1.0) in the Vologda Oblast contribute to the favorable growth and development of crops and weeds. Sometimes, a significant part of the nutrients of fertilizers and soil is spent on the development of weeds. Therefore, the application of fertilizers without herbicides, especially in the area of excessive moisture, does not ensure the efficient use of nutrients. The productivity of crops can be significantly higher with the proper use of chemicals used taking into account the climatic conditions of the region, agrochemical indicators of the soil, varietal characteristics of crops, thresholds of harmfulness of weeds. There are well known balance methods for calculating the doses of fertilizers for the planned yield of agricultural crops, for the planned increase in yield, etc. The applied method for calculating the doses of fertilizers using differentiated balance coefficients, proposed by Yu.P. Zhukov, provides a planned level of environmentally friendly crop rotation production with simultaneous regulation of soil fertility [1-11].

The purpose of the research is to study the effect of fertilizers calculated using balance factors on the background and without the use of herbicides in crop rotation.

\section{Materials and methods}

The studies were conducted in 2010-2013 in a long field experiment laid down in 1990 at the training experimental field of the Vologda State Dairy Farming Academy. According to the certificate of long experiment No. 164, is was included in the register of the State network of experiments with fertilizers and other agrochemical means.
The soil of the experimental plot was sod-podzolic medium loamy with an average level of cultivation. In 1990, the arable soil layer of the experimental plot had the following agrochemical characteristics and contained: $114 \mathrm{mg}$ of mobile potassium per $1 \mathrm{~kg}$ of soil, $266 \mathrm{mg}$ of mobile phosphorus per $1 \mathrm{~kg}$ of soil, and $3.28 \%$ of humus.

In 2007, in the control version (without fertilizers), the content of mobile potassium decreased to $55 \mathrm{mg} / \mathrm{kg}$, that of mobile phosphorus to $132 \mathrm{mg} / \mathrm{kg}$, and the content of humus decreased to $2.56 \%$.

Studies on the effect of various doses of fertilizers and herbicides on crop yields and crop quality were carried out in a 4-field crop rotation deployed in space and time. Crop rotation scheme was as follows: oatmeal mixture for green mass (Lgovskaya 22 vetch, Borrus oats), winter rye (Volkhov varieties), potato (Elizaveta varieties), barley (Vybor varieties)

The repetition of the experiment is fourfold, the allocation of plots is complicated and systematic. The area of one plot is $140 \mathrm{~m}^{2}(10 \mathrm{~m} \mathrm{x} 14 \mathrm{~m})$. The experience scheme in the years of research included options with fertilizers: 1 variant had no fertilizers (reference); variant 2 used fertilizers for sowing and planting crops (minimum dose); variants 3 and 4 are two versions of the studied fertilizer systems, differing in the dose of nitrogen; variant 5 used an organomineral system equivalent in dose to the third variant of the mineral fertilizer system.

In the experiment, 2 factors were studied: (A - types and doses of fertilizers) and (B - herbicides: without treatment (1) and with treatment (2)). To study the effectiveness of the estimated doses of fertilizers in combination with herbicides accepted in practice, the latter were treated with half of the plot. Herbitox herbicide with a consumption rate of 0.7 1/ha was used on the oatmeal mixture; on winter rye Herbitox was used with a rate of $1 \mathrm{l} / \mathrm{ha}$; on potatoes Lapis lazuli was used

Corresponding author: Dekanagro@molochnoe.ru 
with a rate of $1.0 \mathrm{~kg} / \mathrm{ha}$; on barley Secator TURBO was used (oil dispersion) with a rate of $0.067-0.07$ 1/ha.

Fertilizer doses were calculated to obtain the following planned yields: $3.5 \mathrm{t} / \mathrm{ha}$ of winter rye, $25 \mathrm{t} / \mathrm{ha}$ of potatoes, $3.5 \mathrm{t} / \mathrm{ha}$ of barley and $25 \mathrm{t} / \mathrm{ha}$ of oatmeal mixture.

In the study, a calculation with balance coefficients $\mathrm{Kb})$ was used according to the formula: $\mathrm{Kb}=(\mathrm{V} / \mathrm{D}) * 100 \%$, where $\mathrm{V}$ is the nutrient removal by culture, $\mathrm{D}$ is the dose of fertilizer used. The balance ratios of phosphorus and potassium in the third, fourth and fifth variants were $100 \%$ (zero balance) and $150 \%$ (negative balance), respectively. The nitrogen balance coefficients in the third and fifth variants were $120 \%$ (negative balance), and in the fourth variant they were $80 \%$ (positive balance).

Phosphate-potassium fertilizers in the form of double superphosphate and potassium salt and $40 \mathrm{t} / \mathrm{ha}$ of peatand-peat compost for potatoes were applied for autumn plowing.
In the spring, during the pre-sowing cultivation, nitrogen fertilizers were introduced in the form of ammonium nitrate. When sowing, winter nitrogen rye, oatmeal mixture and barley were added with complex nitrogen-phosphorus-potassium fertilizer, and nitroammophos was used for potatoes (in variant 2, only when sowing or planting).

The content of nutrients in plant and soil samples was determined by standard methods $[12,13]$. Experimental data were processed by analysis of variance according to B.A. Dospekhov [14].

\section{Results and discussion}

Weather conditions during the years of research were characterized by a lack of moisture in all years of research and hot weather in the summer of 2010 and 2011 , which led to a low yield of oatmeal mixture and spring barley (due to the short growing season of these crops). A longer period of vegetation of potatoes and winter rye allowed these crops to form a higher yield.

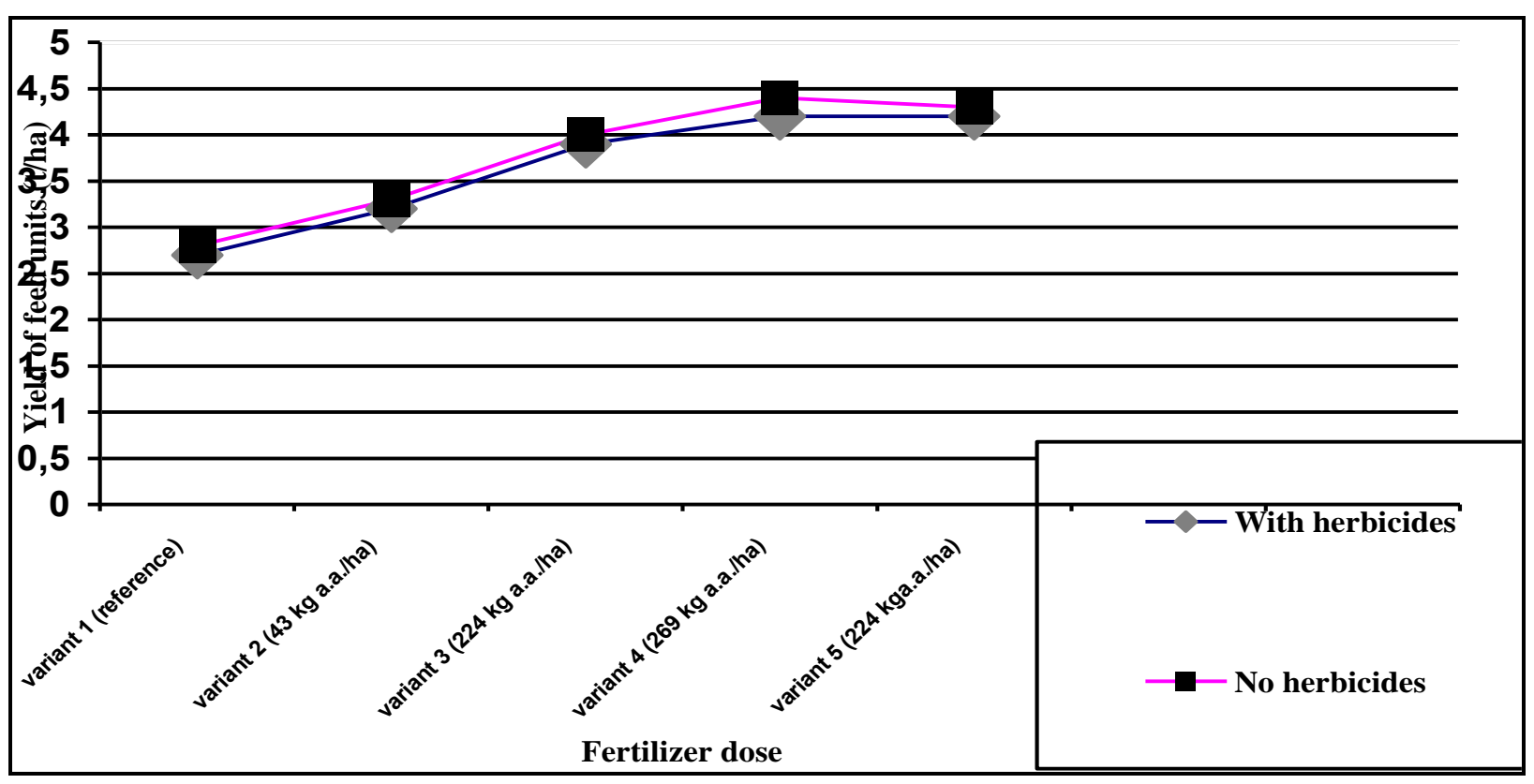

Fig. 1. Collection of feed units by crop rotation crops averaged over years of research (t/ha)

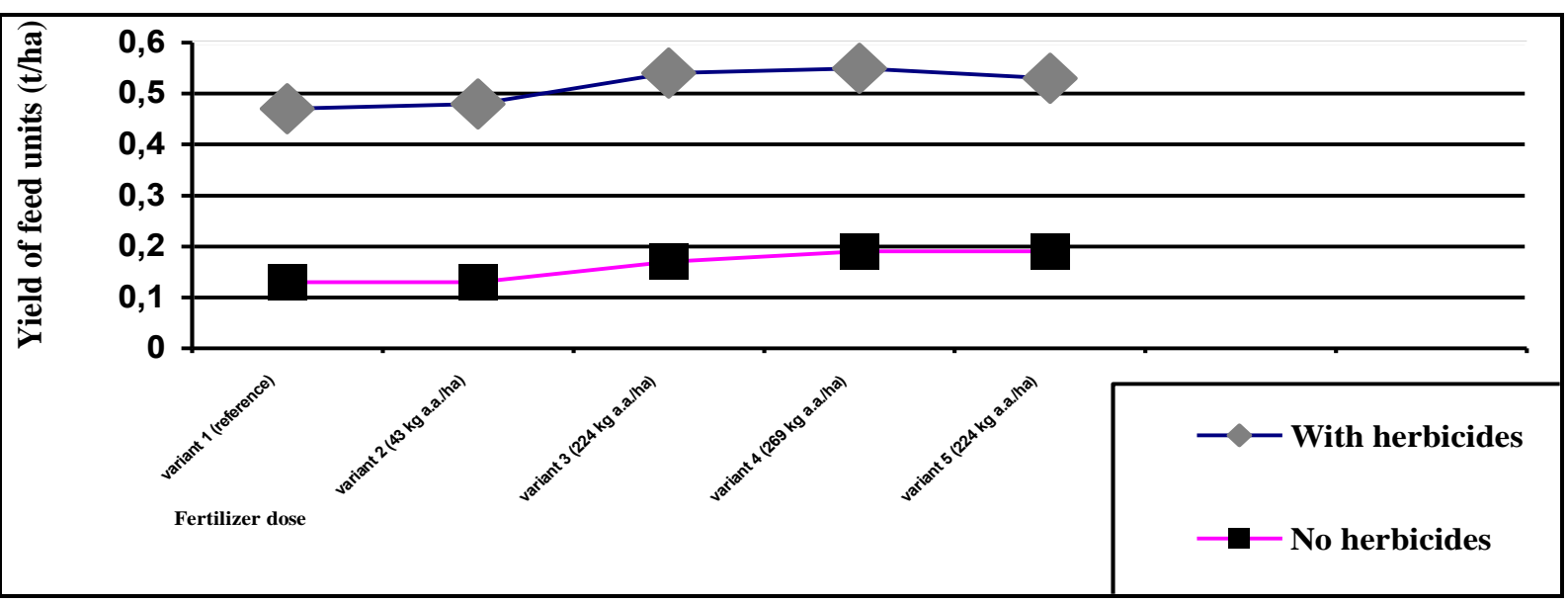

Fig. 2. Removal of feed units by weeds in crop rotation averaged over years of research (t/ha) 
The collection of feed units by crop rotation crops without fertilizers and herbicides on average over the years of research amounted to $2.7 \mathrm{t} / \mathrm{ha}$ (Fig. 1).

The use of fertilizers for sowing cereals, oatmeal mixture and planting potatoes ( 2 variant) provided an increase of collection of feed units in the reference variant by $18 \%$. The use of calculated fertilizing systems (variants 3-5) contributed to a significant increase in the productivity of crop rotation. Thus, the collection of feed units increased by $44-56 \%$.

Treatment by herbicides with the background of fertilizers provided an increase in the absolute reference of the collection of feed units by cultivated plants by $22-59 \%$.
Weed vegetation yielded $0.47-0.55$ tons of feed units from 1 ha without herbicides and $0.13-0.19 \mathrm{t} / \mathrm{ha}$ with them (Fig. 2).

Fertilizers increased the collection of feed units by weeds by $2-17 \%$. Herbicide treatment significantly reduced the productivity of drowsiness, the removal of feed units by $64-73 \%$.

Treatment with a herbicide, decreases the removal of feed units by weeds and increases crop productivity.

With increasing doses of fertilizers, the removal of nutrients increases (Table 1).

Table 1. Balance coefficients of nutrient use in crop rotation, on average over the years of research

\begin{tabular}{|c|c|c|c|c|c|c|c|c|c|}
\hline \multirow{3}{*}{ Indicator } & \multirow{3}{*}{ Element } & \multicolumn{8}{|c|}{ Variant } \\
\hline & & \multicolumn{2}{|c|}{2} & \multicolumn{2}{|c|}{3} & \multicolumn{2}{|c|}{4} & \multicolumn{2}{|c|}{5} \\
\hline & & 1 & 2 & 1 & 2 & 1 & 2 & 1 & 2 \\
\hline \multirow{3}{*}{$\begin{array}{c}\text { Weighted average annual } \\
\text { removal by cultivated plants } \\
{[\mathrm{kg} / \mathrm{ha}]}\end{array}$} & $\mathrm{N}$ & 68.5 & 73.3 & 92.1 & 96.8 & 105.9 & 110.3 & 101.4 & 106.2 \\
\hline & $\mathrm{P}_{2} \mathrm{O}_{5}$ & 25.4 & 27.3 & 32.2 & 34.3 & 37.9 & 37.9 & 37.4 & 37.4 \\
\hline & $\mathrm{K}_{2} \mathrm{O}$ & 82.6 & 84.4 & 109.5 & 113.1 & 122.5 & 126.3 & 116.9 & 123.8 \\
\hline \multirow{3}{*}{$\begin{array}{c}\text { Weighted average annual } \\
\text { removal by cultivated and } \\
\text { weed plants }[\mathrm{kg} / \mathrm{ha}]\end{array}$} & $\mathrm{N}$ & 84.4 & 76.9 & 110.5 & 101.9 & 126.8 & 115.8 & 120.4 & 112 \\
\hline & $\mathrm{P}_{2} \mathrm{O}_{5}$ & 29.8 & 28.4 & 37.3 & 35.6 & 39.4 & 39.4 & 38.7 & 38.7 \\
\hline & $\mathrm{K}_{2} \mathrm{O}$ & 105.4 & 88.7 & 137.1 & 120.5 & 149.2 & 134.1 & 143.7 & 131.1 \\
\hline \multirow{3}{*}{$\begin{array}{l}\text { Average annual fertilizer } \\
\text { application }[\mathrm{kg} / \mathrm{ha}]\end{array}$} & $\mathrm{N}$ & 14 & 14 & 93 & 93 & 138 & 138 & 93 & 93 \\
\hline & $\mathrm{P}_{2} \mathrm{O}_{5}$ & 17 & 17 & 41 & 41 & 41 & 41 & 41 & 41 \\
\hline & $\mathrm{K}_{2} \mathrm{O}$ & 12 & 12 & 90 & 90 & 90 & 90 & 90 & 90 \\
\hline \multirow{3}{*}{$\begin{array}{l}\mathrm{K}_{\mathrm{b} \text { actual }} \text { disregarding weed } \\
\text { plants }[\%]\end{array}$} & $\mathrm{N}$ & 506 & 527 & 99 & 104 & 77 & 80 & 109 & 113 \\
\hline & $\mathrm{P}_{2} \mathrm{O}_{5}$ & 149 & 161 & 77 & 82 & 88 & 91 & 88 & 90 \\
\hline & $\mathrm{K}_{2} \mathrm{O}$ & 327 & 313 & 119 & 121 & 134 & 136 & 124 & 132 \\
\hline \multirow{3}{*}{$\begin{array}{c}\mathrm{K}_{\mathrm{b} \text { actual taking into account }} \\
\text { weed plants [\%] }\end{array}$} & $\mathrm{N}$ & - & - & 119 & 110 & 92 & 84 & 129 & 120 \\
\hline & $\mathrm{P}_{2} \mathrm{O}_{5}$ & - & - & 91 & 87 & 96 & 96 & 94 & 94 \\
\hline & $\mathrm{K}_{2} \mathrm{O}$ & - & - & 152 & 134 & 166 & 149 & 160 & 146 \\
\hline
\end{tabular}

The minimum dose of fertilizers $\left(\mathrm{N}_{14} \mathrm{P}_{17} \mathrm{~K}_{12}\right)$ increases nitrogen removal by crops by $20 \%$, phosphorus by $18 \%$ and potassium by $26 \%$.

With the introduction of estimated doses of fertilizers, the removal of nutrients from cultivated crops is significantly increased. Indeed, compared to the version without fertilizers, the removal increased by 62-86\% for nitrogen, by $50-76 \%$ for phosphorus and by $67-87 \%$ for potassium.

The maximum removal of nutrients from the soil and fertilizers by crops was observed on the variant with the maximum dose of nitrogen. Chemical weeding increased the removal of nutrients by crops in relation to the absolute value of the reference variant: by $29-94 \%$ for nitrogen, by $27-76 \%$ for phosphorus, by $29-93 \%$ for potassium.

The calculated actual balance factors with values closer to the planned ones were obtained taking into account the removal of nutrients from weeds.

Weed vegetation without the use of herbicides uses $15-20 \%$ of nitrogen, 6-14\% of phosphorus and 32-36\% potassium from fertilizers and soil.

After chemical weeding weeds use less nitrogen by 4 to $7 \%$, phosphorus by 4 to $5 \%$ and potassium by 13 to $14 \%$.

On average, during the years of research when using fertilizers, the crop rotation ensured a positive nitrogen balance for variant 4 and a negative balance for variants
3 and 5. The positive balance of phosphorus was ensured by the use of fertilizers and the combined use of fertilizers and herbicides.

Actual balance coefficients of utilization of nutrients from fertilizers and soil were lower than those planned for nitrogen and potassium when planning the negative balance by 7-21 and 14-31 \%, respectively; for phosphorus when planning the zero balance the coefficients were lower by $9-23 \%$. Herbicides increased the nutrient removal of crops and brought the actual balance factors closer to the planned ones.

The result of the negative balance and $\mathrm{Kb}$ exceeding $100 \%$ indicate that a high level of yield of the studied crops was achieved partially due to the use of soil nutrients (soil fertility), especially for variant 2 . The limiting factor in the experiment was a lack of potassium, therefore, possibly, a higher yield was not obtained for this reason.

In other cases, there is a positive balance of elements (Kb below $100 \%$ ), therefore, there should be an increase in the content of soil nutrition elements.

The degree of conversion of fertilizers into rotation crop feed units was quite high (Fig. 3).

The highest conversion was achieved when introducing minimum fertilizer dose. When applying the estimated doses of fertilizers (increasing doses of fertilizers), a decrease in the conversion degree of fertilizers into feed units was noted. 


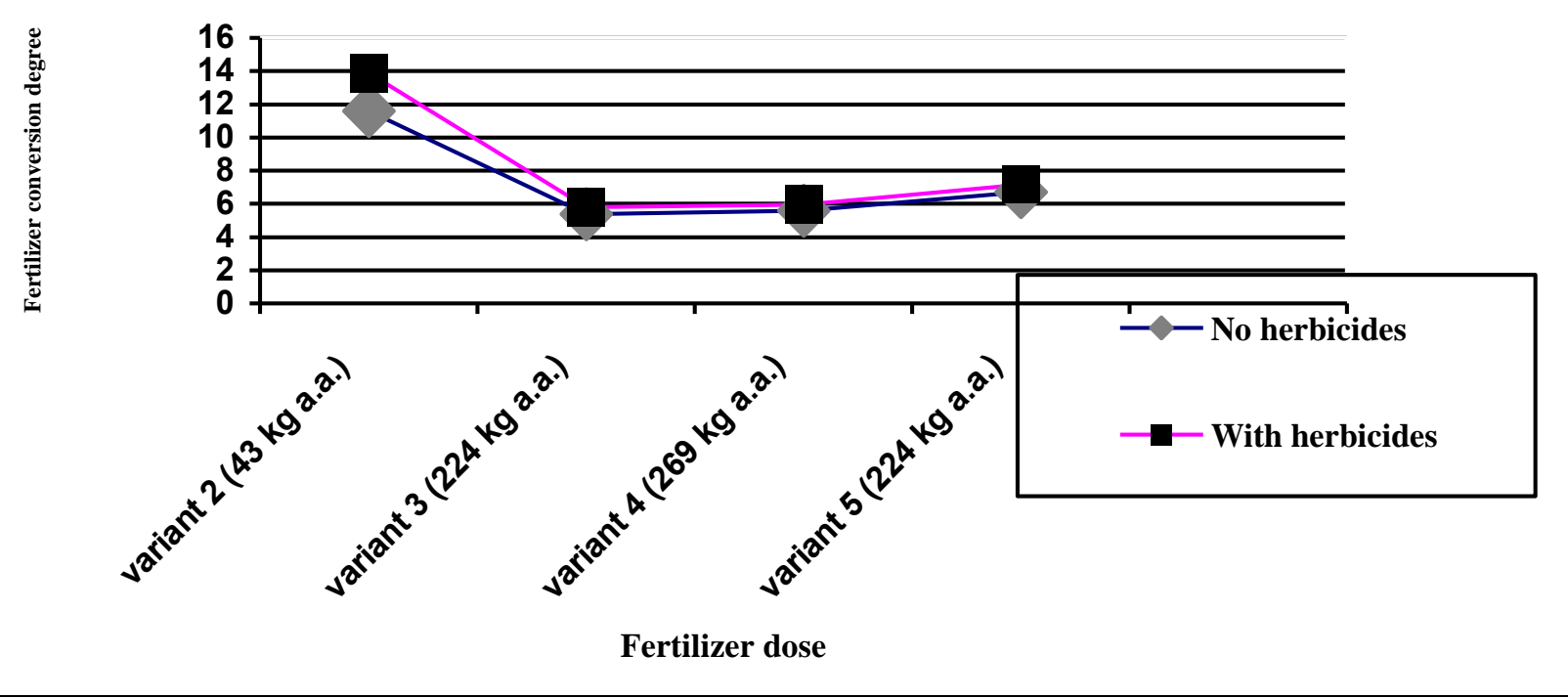

Fig. 3. Conversion degree of fertilizers by collection of feed units of rotation crops, averaged over years of research ( $\mathrm{kg} / \mathrm{kg}$ of a.a.)

The degree of conversion of fertilizers into feed units on average over the years of research amounted to $13.9-5.36 \mathrm{~kg} / \mathrm{kg}$ a.a. When processing crop rotation crops with herbicides, an increase in conversion was observed at a minimum dose of fertilizers (43 kg a.a./ha) by $2.3 \mathrm{~kg}$, and when using full calculated doses of fertilizers (224-269 $\mathrm{kg}$ a.a./ha) by $0.37-0.44 \mathrm{~kg}$.

The use of the organomineral fertilizer system ensured a higher payment of fertilizers from all the studied calculated doses of fertilizers. These results are confirmed by previous studies.

\section{Conclusion}

Thus, the collection of feed units by rotation crops without fertilizers and herbicides averaged to $2.7 \mathrm{t} / \mathrm{ha}$ over the years of research. Weed vegetation removed $0.47-0.55$ tons of feed units from 1 ha without herbicides and $0.13-0.19 \mathrm{t} / \mathrm{ha}$ when those were applied. Conversion of fertilizers by rotation crops corresponded to $13.9-5.36 \mathrm{~kg}$ of feed units per $1 \mathrm{~kg}$ of a.a. When treating crops with herbicides, the payment of fertilizers increased against the background of fertilizers of $43 \mathrm{~kg}$ a.a./ha by $2.3 \mathrm{~kg}$ of feed units, and when using full calculated doses of fertilizers $(224-269 \mathrm{~kg}$ a.a./ha) by $0.37-0.44 \mathrm{~kg}$ of feed units.

\section{References}

1. Yu.P. Zhukov, Fertilizer system in farms of the NonBlack Earth (Moskovskiy rabochiy, Moscow, 1983)

2. Yu.P. Zhukov, Nutrient balance as a predictive ecological indicator of soil fertility and crop productivity, Agrochem., 7, 35-45 (1996)

3. O.V. Chukhina, Yu.P. Zhukov, Productivity of crops and changes in agrochemical indicators of sod-podzolic soil in crop rotation using various doses offertilizers, Agrochem., 5, 20-28 (2015)

4. O.V. Chukhina, V.V. Surov, Effect of fertilizers and micropreparations on the productivity and removal of nutrients by crops of a field crop rotation link, Soil fertility, 3(78), 18-22 (2014)

5. L.M. Derzhavin, Integrated use of agrochemicals in grain farming, Agrochem., 12, 3-17 (2007)

6. V.I. Dolzhenko, T.A. Makhankova, A.S. Golubev et al., Effectiveness of the new combined herbicide for the protection of crops, Agro XXI, 10-12, 22-24 (2012)

7. V.G. Doronin, E.N. Ledovsky, V.I. Dmitriev, Effectiveness of the protection of crops in the south of Western Siberia, Protect. and Quarant. of Plants, 10, 22-24 (2012)

8. A.A. Zavalin, V.I. Potapov, Harvest formation and grain quality of barley and oats depending on doses and timing of nitrogen application, Agrochem., 11, 20-26 (1996)

9. E.V. Kapylov, Influence of soil-protective methods of tillage on the harmfulness of the weed component on the slope lands of the Non-chernozem zone, Agro XXI, 4-6, 13-16 (2009)

10. Z.I. Usanova, I.V. Shalnov, Influence of the background of mineral nutrition and density on the size and quality of the crop of an early ripening hybrid of corn in the Upper Volga, Feed product., 2, 21-23 (2013)

11. A.A. Zamaydinov, M.M. Nafikov, V.N. Fomin, Rationale for the use of biological factors of barley cultivation in the forest-steppe of the Volga region, in Proc. of the int. sci.-pract. Conf. dedicated to the 50th anniversary of the Institute of Economics "Current Trends and Actual Problems of the Development of an Innovative Economy," 104-106 (Kazan SAU Publishing House, Kazan, 2011)

12. N.S. Almetov, G.U. Mariysky, L.S. Chernova, A.A. Zavalin, Barley productivity when using mineral fertilizers on sod-weakly podzolic soils, Soil fertility, 3, 2-4 (2012)

13. G.I. Bazdyrev, N.G. Reshetnikova, Effectiveness of the elements of intensification of agriculture in the 
link of crop rotation "green manure - winter triticale”, Soil fertility, 3, 4-7 (2012)
14. B.A. Dospekhov, The methodology of field experience (with the basics of statistical processing of research results), 5rd ed. (Agropromizdat, Moscow, 1985) 